\title{
Genotype-Environment Interactions: Cognitive Aging and Social Factors
}

\author{
Chandra A. Reynolds,' Margaret Gatz,, ${ }^{2,3}$ Stig Berg, ${ }^{4,2}$ and Nancy L. Pedersen ${ }^{3,2}$ \\ ' University of California, Riverside, California, United States of America \\ ${ }^{2}$ University of Southern California, California, United States of America \\ ${ }^{3}$ The Karolinska Institute, Stockholm, Sweden \\ ${ }^{4}$ Jönköping University, Sweden
}

\begin{abstract}
T he possibility of genotype-environment interaction for memory performance and change was examined in 150 monozygotic (MZ) twin pairs from the Swedish Adoption Twin Study of Aging (SATSA). We used an MZ twin pair difference approach to examine the possibility that genotype was associated with intrapair variability and thus suggestive of genotype-nonshared environment interactions. Multiple 'variability genes' were found for longitudinal change in a semantic memory task including candidates coding for apolipoprotein E (APOE) and estrogen receptor alpha (ESR1) as well as serotonin candidates (HTR2A and 5HTT). One candidate also related to variability in change in episodic memory (5HTT). Of the significant associations observed, generally results indicated that MZ pairs who carry putative risk alleles were less variable than noncarriers, suggesting that noncarriers may be more sensitive to environmental contexts. We sought to 'contextualize' the possible nonshared environmental influences for found gene-environment $(G \times E)$ effects by considering intrapair differences in measured social and stress factors, including social support, life events and depressive symptoms. Results suggested that nonshared environmental influences associated with depressive symptoms may moderate the $\mathrm{G} \times \mathrm{E}$ relationship observed for ESR1 and APOE and longitudinal semantic memory change whereby noncarriers of putative risk alleles may be relatively more sensitive to depressionevoking environmental contexts than carriers of the risk allele. Thus, the contexts that facilitate or reduce depressive symptoms may affect semantic memory resiliency dependent on genotype. Further work ought to consider larger sample sizes as well as consider additional social and contextual factors.
\end{abstract}

Cognitive health in old age reflects accumulating biological, environmental and random influences over the life course that may interact with one another. With age, environmental factors, particularly personspecific factors, play an increasingly important role in individual differences in cognitive change across domain (Reynolds et al., 2005). These nonshared environmental influences may suggest the presence of gene-environment interactions $(G \times E)$. If not directly modeled, $\mathrm{G} \times \mathrm{E}$ will become part of the estimate for nonshared environment (Falconer, 1989). Thus, it is important to consider specific environmental factors that may affect one's cognitive resiliency and to look at how these may interact with genotypic characteristics. However, relatively little is known about either specific environmental candidates or specific gene candidates for cognitive decline let alone potential gene-environment interactions. The only gene to have received much attention is $A P O E$, which codes for the primary cholesterol transporter in the brain, apolipoprotein E (apoE). Social environment and emotional influences on cognitive aging have received little attention although some relatively recent findings suggest stressful life experiences, social support, and socioecomic factors may influence cognitive change (e.g., Beland et al., 2006; Holtzman et al., 2004; Sachs-Ericsson et al., 2005). No publications to date have examined potential candidate geneenvironment interactions involving social factors and cognitive aging traits.

\section{Candidate Socio-Environmental Factors}

Cognitive reserve in late life may be affected by early life or mid-life environmental factors (see Borenstein et al., 2006; Gatz et al., 2006). Indeed, the riches of good cognitive health in older age may be disproportionately afforded to those who are socioeconomically advantaged in early life, such that health-promoting environments and behaviors may coalesce. Socioeconomic status (SES) and related factors have been examined as measured environmental effects in gene-environment interaction analyses for general intelligence in adolescence (Harden et al., 2007), dementia and AD (see Borenstein et al., 2006). Other social and stress-related factors remain less well

Received 21 November, 2006; accepted 26 January, 2007.

Address for correspondence: Chandra A. Reynolds, Department of Psychology, University of California-Riverside, Riverside, California 92521,USA.E-mail: chandra.reynolds@ucr.edu 
studied in this regard. Social or stress-related factors predictive of cognitive decline and/or dementia include lower social engagement or support, stress, and higher depressive symptoms.

\section{Social Support}

Lower social support and social engagement have been associated with cognitive change in communitybased samples (e.g., Beland et al., 2005; Holtzman et al., 2004). For example, poorer cognitive functioning was associated with lower participation in community activities and lower family support, while cognitive decline over a period of 7 years was associated with lower participation in community events at baseline (Beland et al., 2005). It should also be noted that changes in social participation can occur due to cognitive decline. Cognitive loss can interfere with ability to engage socially; or cognitive loss could create a greater need for social support from family.

\section{Stress}

There is a strong argument based on rodent, primate, and human studies that life stress that occurs early in life or that is chronic may predispose to impaired hippocampal functioning (e.g., Brunson et al., 2005; Hibberd et al., 2000; Magri et al., 2006). There is also some epidemiological evidence supporting an association between life stress and poorer memory performance (e.g., VonDras et al., 2005).

\section{Depression}

The occurrence of depressive symptoms may predict later cognitive decline or dementia (Sachs-Ericsson et al., 2005) although the relationship is unclear. In particular, depressive symptoms might be early indicators of Alzheimer's disease (Wetherell et al., 1999) rather than a risk factor. Indeed stress exposure may lead both to increased depressive symptoms and cognitive change (Duman, 2005).

\section{Candidate Genes}

Candidate genes for cognitive aging traits have been less well studied than for the dementias such as Alzheimer's disease (AD). Dozens of candidates have been examined with respect to $\mathrm{AD}$ with the $A P O E$ gene showing the most consistent association (see Blomqvist et al., 2006; Rogaeva et al., 2006). Relatively few candidate gene association studies have been published for cognitive aging traits, and $A P O E$ is the most well known candidate with associations found for cognitive functioning in general although most consistently for memory performance (see Anstey \& Christensen, 2000). Mixed support has been observed for estrogen receptor alpha (ESR1) and cognitive performance, impairment and AD risk (e.g., Corbo et al., 2006; Kravitz et al., 2006; Porrello et al., 2006; Prince et al., 2001; Yaffe et al., 2002). Some studies have found associations for women but not men (e.g., Porrello et al., 2006) and where an association is found it is often moderated by $A P O E$ e 4 allele status. Indeed, a recent study of men and women suggests that $A P O E$ expression may mediate the relationship between ESR1 variants and $\mathrm{AD}$ risk (Corbo et al., 2006): low serum apoE levels, as observed in those with $\mathrm{AD}$, were observed for ESR1 homozygotes for the PvuII and XbaI variants that also carried the APOE e4 allele. The extent to which ESR1 may be related to nonpathological cognitive change is of interest.

In nondemented twins from the Swedish Adoption Twin Study of Aging (SATSA) study we have observed associations of $A P O E$ with working memory performance and change, $A 2 M$ (which codes for the apoE ligand alpha2-macroglubulin) with episodic figural memory change (Reynolds, Prince, et al., 2006), and association of HTR $2 a$ (which codes for serotonin 2A receptors) with episodic figural memory change (Reynolds, Jansson, et al., 2006).

\section{Gene-Environment Interaction}

Psychosocial factors have been understudied as modifiers of gene-phenotype relationships. Much of what we know relates to physical environment factors or healthrelated factors. For example, studies have indicated moderation of the APOE e4 AD risk association by the occurrence of head injury (e.g., Mayeux et al., 1995) and low paternal SES (Moceri et al., 2000, 2001). The effects of $A P O E$ e4 status coupled with head injury increased the risk of $\mathrm{AD}$ ten-fold which well exceeded the additive effect of each risk factor alone (Mayeux et al., 1995). The increased risk of $\mathrm{AD}$ due to father's manual occupation level was only observed for those who were APOE e4 positive (Moceri et al., 2001). Beyond SES, psychosocial factors measured later in life have not yet been examined as potential modifiers of the relationship between APOE e4 and AD risk.

We know even less about gene-environment interactions for cognitive traits. Neuropsychological performance after head injury has been examined for nondemented patients between the ages of 16 and 65 years where $A P O E$ e 4 carriers showed worse cognitive performance on verbal memory, attentional and perceptual speed tasks 6 months after the injury (Ariza et al., 2006). APOE e4 status when coupled with untreated hypertension predicted poorer cognitive performance in participants from the Nurses' Health Study (Kang et al., 2005). In terms of social factors, higher heritability estimates for childhood and adolescent cognitive ability have been observed as social status and prosperity levels increase suggesting the presence of a $\mathrm{G} \times \mathrm{E}$ interaction (see Harden et al., 2007).

In light of the findings described above that suggest environmental influences may moderate the APOE cognitive performance or dementia risk associations, $A P O E$ may act as a 'variability gene' for normative cognitive change. Whereas typical candidate gene-phenotype association studies examine differences in phenotypic means or disease risk by genotype or allele status, candidate gene association with measures of trait variability, that is, 'variability genes' (Berg et al., 1989), can be viewed as testing gene-environment interaction (Berg et al., 1989; 
Martin, 2000; Martin et al., 1983). A primary strategy is to make use of $\mathrm{MZ}$ twins given that within-pair differences would reflect nonshared environmental influences. For example, Magnus and colleagues (Magnus et al., 1981) observed that $M Z$ twin pairs who carried the $M$ allele in the MN blood system showed less intrapair variation for serum cholesterol values than MZ pairs who were $\mathrm{NN}$ homozygotes. If within-pair differences varied by genotype (e.g., $\mathrm{M}+$ or NN status) that would indicate the presence of gene-nonshared environment interactions, that is, differential sensitivity to the environment dependent on genotype. In the spirit of Berg et al. (1989), the extent to which APOE may be a 'variability gene' in adolescence was examined by comparing within-pair differences among MZ twins for several lipid and lipoprotein traits (plasma cholesterol, triglycerides, and LDL cholesterol, and apoB and apoE lipoproteins) stratified by APOE phenotypes (de Knijff et al., 1993). Patterns of findings suggested that apoE e3e4 pairs were less variable than e2e 3 or e $3 \mathrm{e} 3$ pairs for plasma cholesterol, LDL cholesterol, and apoE lipoprotein across all methods to assess intrapair differences. However, the intrapair differences amongst the different apoE phenotype classes were not significant. The authors concluded that $A P O E$ may not be a variability gene for these plasma lipids and lipoproteins in adolescence.

\section{The Current Study}

Although it appears that APOE may not be a variability gene in adolescence per se (de Knijff et al., 1993), $A P O E$ and other relevant gene candidates may act as variability genes in later adulthood. Longitudinal growth curve analyses of cognitive measures tapping memory abilities (Information, Digit Span, and Thurstone Picture memory task) indicate increasing genetic influences with age that may suggest that in late life new genes come 'online', or genetic influences may become amplified. Indeed, prior studies have suggested $A P O E$ as a candidate for differential memory change. Of particular interest for the current study is the accumulating nonshared environmental variance for all verbal, spatial, memory and perceptual speed traits. The increasing nonshared environmental variance may suggest accumulations of environmental and random factors, as well as unspecified genotype-environment interaction (Falconer, 1989). The extent to which APOE and other candidates such as ESR1 and HTR $2 a$ may be variability genes for memory change is unknown. In the present study on gene-environment interaction we consider APOE as well as other putative $\mathrm{AD}$ candidates to consider whether they influence variability in nonpathological memory change. Using an MZ pair differences approaches (e.g., Berg et al., 1989; Martin, 2000; Martin et al., 1983) we ask the following questions:

1. Is there evidence for genotype-environment interactions for cognitive change traits that tap memory abilities?
2. Do any genotype-environment interactions for cognitive change involve measured social support factors, stress, and depressive symptoms?

\section{$\overline{\text { Methods }}$ \\ Sample}

The analyses focused on $150 \mathrm{MZ}$ pairs in SATSA (see Finkel \& Pedersen, 2004; Pedersen et al., 1991) with data available on the selected cognitive tests from up to five waves of in-person testing (IPT). Of the 150 MZ pairs, 88 were female and 62 were male. Incompleteness of data resulted in variable patterns of data available for the estimated growth parameters (described below). Analyses of cognitive ability level included 148 to 150 pairs. Analyses of linear change included 113 to 121 pairs whilst analysis of nonlinear change included 67 to 72 pairs. In $112 \mathrm{MZ}$ pairs both cognitive and genotype information were available.

Zygosity status was established through serological analysis or analysis of DNA markers for $89 \%$ of the total $150 \mathrm{MZ}$ pairs while for $11 \%$ zygosity was assigned through questionnaire methods. The accuracy of the questionnaire-based methods used is about $98 \%$ in adult twins (Lichtenstein et al., 2002). Of the $112 \mathrm{MZ}$ pairs with both genotypic plus cognitive data, $96 \%$ had zygosity established by serological or DNA marker analysis. In the remaining $4 \%$ (four pairs) only one twin had available DNA information and questionnaire-based zygosity was used.

Dementia status was known for twins in the study with diagnostic information available up to May 2006 based on in-person work-up (through 2001) or medical registry diagnosis (up to May, 2006). We set to missing cognitive data that occurred after the estimated age of onset for any twins identified as demented. Subsequently, 22 pairs where one or both became demented had at least one time point of cognitive data prior to age of onset in the current study (three pairs were concordant for dementia). Of the 22 pairs, 12 pairs had at least two time-points (one concordant for dementia) and only three pairs had three or more time points prior to age on onset (none concordant for dementia).

\section{Measures \\ Cognitive Measures}

For the present study, we selected memory-related measures for which prior analyses indicated increases in nonshared environmental variance (Reynolds et al., 2005). All tap some aspect of memory: (a) Information subtest, a typical test of crystallized intelligence requires semantic memory (Jonsson \& Molander, 1964); (b) Digit Span, the sum of forward and backward includes working memory and attention (Jonsson \& Molander, 1964); and (c) Thurstone Picture Memory recognition task requires nonverbal episodic memory (Thurstone, 1938). Prior to growth model 
analysis, all scores were transformed to a per cent correct scale.

Nonlinear growth curve models were fit to all SATSA twins for Information and Thurstone Picture Memory performance data from up to five time points and using full maximum-likelihood estimation of fixed and random effects (cf. Finkel et al., 2003; Reynolds et al., 2005; Reynolds, Jansson, et al., 2006) ignoring pair dependency. (Not accounting for pair status could affect standard errors of the average growth parameters, but significance testing was not of interest in this phenotypic analysis whose object was to estimate to individual growth parameters.) The growth curves were centered at age 65 years and thus the intercept and linear slope reflected the average ability and rate of change at 65 years, respectively, and the quadratic parameter the acceleration in change throughout the age range. A linear model was fit to the Digit Span data as the quadratic model was not supported; thus, the linear slope was constant throughout the age range. Individual empirical Bayes (EB) estimates were requested for the growth parameters. EB estimates for linear and quadratic were set to missing if there were fewer than two time points (linear) or fewer than three time points (quadratic). For the current study, data were only considered for further analysis if participants were members of $\mathrm{MZ}$ pairs and where both in the pair had available EB estimates.

\section{Social and Stress Measures}

Measures tapping social support and life events were available from the first in-person assessment (IPT1). Depressive symptoms using the CES-D scale (Center for Epidemiologic Studies-Depression; Radloff, 1977) were available from the second in-person assessment (IPT2).

Social support. Nine questions from an adapted version of the ISSI (Henderson et al., 1980) measured observed and perceived social support. Each of the questions determined the quantity of support of various types (number of friends, family, etc, that one could rely on) and perceived support; that is, how satisfactory was the support that they received. Responses to the observed support items and perceived support items were separately standardized and summed to quantify objective and subjective support, respectively (see Bergeman et al., 1990).

Life Events. Twenty life event items (e.g., retirement, death of child, divorce) from an adapted version of the Social Readjustment Rating Scale (Holmes \& Rahe, 1967; Persson, 1980) were weighted by the respondent's rating of perceived importance ratings and summed (Plomin et al., 1990). In addition, a subset of events that were considered 'uncontrollable' were weighted and summed.

Depressive symptoms. Depressive symptoms were measured by the CES-D measure (Center for Epidemiologic Studies-Depression; Radloff, 1977).
The current analyses used the total score based on a sum of 20 items rated on a 0 - to 3-point scale.

\section{Genotypes}

Genotyping was performed on DNA extracted from blood samples collected during the third in-person measurement occasion (IPT3). Genotyping of 16 SNPs across 15 candidates are available for the present analyses, including: Apolipoprotein E (APOE), $\alpha 2-$ macroglobulin $(A 2 M)$, angiotensin converting enzyme $(A C E)$, advanced glycosylation end product-specific receptor $(A G E R)$, butyrylcholinesterase (BCHE), cathepsin D (CTSD), dihydrolipoamide s-succinyltransferase $(D L S T)$, estrogen receptor 1 alpha (ESR1), serotonin 5-HT-2A receptor (HTR2A), 5-hydroxytryptamine transporter $(5 H T T)$, insulin-degrading enzyme (IDE), interleukin 1 receptor alpha (ILA1), low density lipoprotein receptor-related protein 1 (LRP1), nitric oxide synthase 3 (NOS3), tumor necrosis factor receptor superfamily, member 6 gene (TNFRSF6). Most were prior candidates for AD (see Blomqvist et al., 2006), and others for depression and normative memory performance. The candidates can be loosely organized in terms of pathways, such as those connected to amyloid deposition (APOE, A2M, $B C H E, C A T D, L R P 1)$, cardiovascular disease (ACE), estrogen (ESR1), inflammation (AGER, ILA1, TNFRFS6), insulin (IDE), oxidation (NOS3, DLST), and serotonin (5HTT, 5HTR2A). In $28 \%$ of the 112 informative $\mathrm{MZ}$ pairs (cognitive data plus genotype information) only one twin was genotyped and the resultant genotypes were assigned to both twins.

Identification of the candidate SNP's are available in Appendix A. With the exception of the 5HTT and $5 H T R 2 A$ candidates, all SNPS (or insertion-deletion) were sequenced using the dynamic allele-specific hybridization (DASH) method (Prince \& Brookes, 2001; Prince et al., 2001). Details of genotyping for the 5HTT and 5HTR2A candidates are described in Jansson et al. (2003). Hardy-Weinberg equilibrium (HWE) was tested using all available SATSA twins by randomly splitting $\mathrm{MZ}$ and dizygotic (DZ) twin pairs into two samples and testing HWE on both samples. HWE was found for 14 of 15 candidates in both samples $(p \geq .05)$. LRP1 failed in one out of the two twin samples tested. Resequencing of LRP1 excluded genotyping error; rather, the rarity of the TT genotype may have led to significance. Bonferroni correction based on 15 tests suggested LRP1 would achieve HWE.

\section{Analyses}

Analyses proceeded in three stages. First, we tested for heterogeneity using the method proposed by Fisher (1925) before proceeding to test whether $\mathrm{G} \times \mathrm{E}$ effects may be present for the empirical Bayes (EB) estimates. This was done for untransformed EB estimates as well as for rank-normalized EB estimates. Second, to test for specific candidate gene-environment interactions we conducted variance ratio tests (Martin et al., 1983) 
Table 1

Analysis of Heterogeneity: Fisher (1925) Test

\begin{tabular}{|c|c|c|c|c|c|c|c|}
\hline & \multicolumn{6}{|c|}{ EB estimates } & \multirow{2}{*}{$\begin{array}{c}\text { Rank - normal } \\
\text { EB estimates }\end{array}$} \\
\hline & & $\begin{array}{l}\text { Average pair } \\
\text { difference }\end{array}$ & $\begin{array}{l}\text { Average squared } \\
\text { pair difference }\end{array}$ & $\begin{array}{c}\text { Comparison } \\
\text { of differences }\end{array}$ & & & \\
\hline Trait & $N$ & $\bar{d}$ & $\overline{d^{2}}$ & $\overline{d^{2}}-\frac{\pi}{2} \bar{d}^{2}$ & $S E$ & $t$ & $t$ \\
\hline \multicolumn{8}{|l|}{ Information } \\
\hline Ability at 65 years & 150 & 8.40 & 131.51 & 20.58 & 5.71 & $3.60^{* *}$ & 0.97 \\
\hline Linear slope 65 years & 121 & 0.11 & 0.03 & 0.01 & $1.32 \mathrm{E}-03$ & $6.57^{* *}$ & $3.40^{* *}$ \\
\hline Quadratic change & 72 & 0.03 & $1.92 \mathrm{E}-03$ & $5.00 \mathrm{E}-04$ & $1.20 \mathrm{E}-04$ & $4.15^{* *}$ & $2.26^{*}$ \\
\hline \multicolumn{8}{|c|}{ Thurstone Picture Memory } \\
\hline Ability at 65 years & 148 & 7.60 & 89.44 & -1.27 & 3.91 & -0.33 & -1.36 \\
\hline Linear slope 65 years & 113 & 0.16 & 0.05 & 0.01 & $2.60 \mathrm{E}-03$ & $4.32^{* *}$ & $2.17^{*}$ \\
\hline Quadratic change & 67 & 0.01 & $3.61 \mathrm{E}-04$ & $5.45 \mathrm{E}-05$ & $2.35 \mathrm{E}-05$ & $2.32^{*}$ & $1.64^{t}$ \\
\hline \multicolumn{8}{|l|}{ Digit Span } \\
\hline Ability at 65 years & 150 & 5.83 & 56.26 & 2.80 & 2.44 & 1.15 & 0.59 \\
\hline Linear slope & 120 & 0.09 & 0.01 & $1.50 \mathrm{E}-03$ & $6.45 \mathrm{E}-04$ & $2.32^{*}$ & $2.10^{*}$ \\
\hline
\end{tabular}

for each gene candidate where significant heterogeneity was found for the EB estimates. Lastly, we examined the association of absolute pair differences in EB estimates of cognitive change (linear or quadratic) to absolute pair differences in social and stress measures in a series of regression analyses. Transformations of the absolute pair difference variables were necessary to reduce nonnormality. For the social environment pair difference variables log transformation to base 10 was used. However, pair differences in EB growth parameter estimates were resistant to typical transformation and thus we rank-normalized and standardized the absolute pair difference values prior to analysis.

\section{Results}

\section{Heterogeneity Tests}

We first performed heterogeneity tests as outlined by Fisher (1925; see also Martin et al., 1983). The results of this test, if significant, would suggest mixtures of distributions of differences, and thus would give some confidence to proceed with formal tests of candidate $\mathrm{G} \times \mathrm{E}$. The Fisher (1925) heterogeneity test in effect compares the mean of squared pair differences to the mean of absolute pair differences. The comparison is expected to be greater than 0 , thus we used a onetailed significance criteria. Table 1 reports the findings for untransformed and rank-normalized EB estimates for growth, to examine the extent to which rescaling may reduce the potential $\mathrm{G} \times \mathrm{E}$ effect. A $t$ statistic was constructed with degrees of freedom based on the number of $\mathrm{MZ}$ pairs less one. Generally the observed heterogeneity effects for the untransformed EB growth parameters estimates were resistant to rescaling although not invariably, that is, the intercept for Information became nonsignficant and the quadratic change estimate for Thurstone's Picture Memory task was at trend significance. However, transformation may remove true $\mathrm{G} \times \mathrm{E}$ effects and thus we proceeded with $G \times E$ variance ratio tests on untransformed variables although caution is warranted in over interpretation of effects.

\section{Variance Ratio Test: $\mathbf{G} \times \mathbf{E}$}

After finding evidence of heterogeneity, we proceeded with tests of genotype-environment interaction for all gene candidates, where we compared within-pair differences for those pairs who carried a putative risk allele versus those who did not carry the risk allele (e.g., $A P O E$ e4 carriers versus noncarriers; see Martin et al., 1983). The results of the variance ratio test will suggest whether particular genotypes may be more sensitive to as yet anonymous nonshared environmental factors, resulting in greater environmental variability, or those that may be relatively impervious to environmental factors and show smaller environmental variability. Based on prior literature we identified particular alleles as being risk alleles (e.g., APOE e4) and otherwise the less frequent allele was considered as the risk allele. Mean squared errors (MSE) for each genotype were estimated from analysis of variance (ANOVA) of twin pair number predicting the estimated EB growth parameter estimates. The variance ratio test was then conducted by taking the largest MSE over the smaller MSE and comparing the resulting $F$ statistic to the appropriate one-sided F-table and then doubling the $p$ value as this is considered a two-tailed test with no specific prediction of which genotype group would show the larger 
Table 2

Variance Ratio Test of Genotype-Environment Interaction for Information Subtest

\begin{tabular}{|c|c|c|c|c|c|c|c|c|c|c|c|c|}
\hline \multirow[b]{3}{*}{ Gene } & \multicolumn{6}{|c|}{ Linear change at 65 years } & \multicolumn{6}{|c|}{ Quadratic } \\
\hline & \multicolumn{2}{|c|}{$M S E$} & \multicolumn{10}{|c|}{ MSE } \\
\hline & $\begin{array}{l}\text { No risk } \\
\text { allele }\end{array}$ & $\begin{array}{l}\text { Risk } \\
\text { allele }\end{array}$ & $N-$ & $N_{+}$ & $\begin{array}{c}\text { Risk: } \\
\text { not risk }\end{array}$ & $F$ & $\begin{array}{c}\text { No risk } \\
\text { allele }\end{array}$ & $\begin{array}{l}\text { Risk } \\
\text { allele }\end{array}$ & $N-$ & $N+$ & $\begin{array}{c}\text { Risk: } \\
\text { not risk }\end{array}$ & $F$ \\
\hline APOE(E4) & 0.02 & 0.02 & 70 & 28 & 1.25 & 1.25 & $1.3 \mathrm{E}-03$ & $2.6 \mathrm{E}-04$ & 49 & 22 & 0.20 & $5.02^{* * *}$ \\
\hline ACE(I) & 0.02 & 0.02 & 21 & 75 & 0.74 & 1.35 & $4.2 \mathrm{E}-04$ & 1.1E-03 & 12 & 59 & 2.61 & $2.61^{\mathrm{t}}$ \\
\hline A2M(DEL) & 0.02 & 0.02 & 69 & 27 & 1.08 & 1.08 & 8.1E-04 & $1.4 \mathrm{E}-03$ & 50 & 21 & 1.69 & 1.69 \\
\hline $\operatorname{AGER}(T)$ & 0.01 & 0.02 & 69 & 28 & 1.41 & 1.41 & $9.9 E-04$ & $9.2 \mathrm{E}-04$ & 51 & 20 & 0.93 & 1.08 \\
\hline $\mathrm{BCHE}(\mathrm{A})$ & 0.02 & 0.02 & 66 & 31 & 0.91 & 1.10 & 8.1E-04 & $1.2 \mathrm{E}-03$ & 44 & 27 & 1.52 & 1.52 \\
\hline CATD(T) & 0.02 & 0.01 & 90 & 7 & 0.50 & 2.01 & $1.0 \mathrm{E}-03$ & 4.4E-04 & 65 & 5 & 0.43 & 2.32 \\
\hline DLST(A) & 0.02 & 0.01 & 27 & 71 & 0.66 & 1.52 & 1.1E-03 & $9.3 \mathrm{E}-04$ & 14 & 57 & 0.82 & 1.22 \\
\hline $\operatorname{ESR} 1(\mathrm{G})$ & 0.01 & 0.03 & 66 & 29 & 2.15 & $2.15 *$ & $1.2 \mathrm{E}-03$ & 5.1E-04 & 51 & 20 & 0.44 & $2.28 *$ \\
\hline 5HTR2(A) & 0.02 & 0.01 & 50 & 46 & 0.66 & 1.52 & $1.4 \mathrm{E}-03$ & $6.6 \mathrm{E}-04$ & 32 & 38 & 0.48 & $2.08^{*}$ \\
\hline $5 \mathrm{HTT}(\mathrm{G})$ & 0.01 & 0.03 & 71 & 26 & 2.63 & $2.63^{* *}$ & 6.6E-04 & $2.0 \mathrm{E}-03$ & 54 & 17 & 3.01 & $3.01^{* *}$ \\
\hline $\operatorname{IDE}(C)$ & 0.01 & 0.02 & 65 & 33 & 1.37 & 1.37 & $9.6 \mathrm{E}-04$ & 9.9E-04 & 46 & 25 & 1.03 & 1.03 \\
\hline $\mathrm{ILA}(\mathrm{T})$ & 0.02 & 0.02 & 60 & 38 & 1.05 & 1.05 & $1.2 \mathrm{E}-03$ & 7.0E-04 & 42 & 29 & 0.61 & 1.65 \\
\hline $\operatorname{LRP}(C C)$ & 0.01 & 0.02 & 18 & 78 & 2.01 & 2.01 & $3.5 \mathrm{E}-04$ & 1.1E-03 & 14 & 56 & 3.16 & $3.16^{*}$ \\
\hline NOS3(T) & 0.01 & 0.02 & 52 & 46 & 1.40 & 1.40 & $1.0 \mathrm{E}-03$ & $9.4 \mathrm{E}-04$ & 34 & 37 & 0.94 & 1.07 \\
\hline $\operatorname{TNF}(G)$ & 0.02 & 0.02 & 33 & 65 & 1.11 & 1.11 & 1.1E-03 & $9.2 \mathrm{E}-04$ & 25 & 46 & 0.86 & 1.16 \\
\hline
\end{tabular}

Note: ${ }^{t} p<.10 ;{ }^{*} p<.05 ;{ }^{* *} p<.01 ;{ }^{* * *} p<.001$

Risk allele (or genotype) in parentheses next to gene symbol. $M S E=$ Mean squares error as a measure of within-pair variability. $N-=$ the number of MZ pairs who do not carry the putative risk allele or do not have the risk genotype (i.e., LRP). $N_{+}=$the number of MZ pairs who do carry the putative risk allele or have the risk genotype (i.e., LRP).

variance. In addition we report the ratio of MSEs of the risk versus nonrisk groups (see Tables 2 and 3). If the risk to nonrisk ratio is above 1.0 then the $M Z$ pairs who are risk allele carriers show greater intrapair variability and would be characterized as more sensitive to environmental factors than noncarriers. If the risk ratio is less than 1.0 then the risk allele carriers show less variability than noncarriers; in this case, those who carry risk alleles would be characterized as relatively more impervious to environmental factors.

\section{Semantic Memory (Information)}

Table 2 reports variance ratio tests for the linear and quadratic EB estimates for Information. Results indicate significant $\mathrm{G} \times \mathrm{E}$ effects for the linear change component at 65 years for ESR 1 and $5 H T T$ where those with the risk alleles were more than two times as variable as noncarriers. Results indicate multiple significant $\mathrm{G} \times \mathrm{E}$ effects for the quadratic change component for: (1) APOE, ESR1 and 5HTR2A where carriers were less variable than noncarriers, and (2) 5HTT and LRP1 where carriers were three times as variable as noncarriers (see Figure 1). Trend significance was observed for $A C E$. The intercept (information performance at 65 years) also exhibited two significant genotype-environment interactions (not shown in Table 2): CATD with a ratio of .21 and HTT with a ratio of 1.92. Trend significance was observed for $A P O E$ with a ratio of .57 for the risk allele carriers (e4) versus nonrisk MZ pairs. Overall, ESR1 and 5HTT both showed association with intrapair variability for the linear and quadratic EB estimates. However, ESR1 risk carriers show greater intrapair variability in linear slope at age 65 years yet smaller intrapair variability in quadratic estimates (as well as for intercept although not significant). For 5HTT, risk carriers showed significantly higher variability in intercept, linear trend at age 65 and quadratic than nonrisk carriers.

\section{Episodic Memory (Thurstone)}

Table 3 reports variance ratio tests for the linear and quadratic parameters for Thurstone Picture Memory recognition test. Results indicate significant $G \times E$ effects for the linear change component at 65 years for: (1) CATD where those carrying the risk allele were less variable than noncarriers, and (2) IDE where those carrying the risk allele were more variable than noncarriers. Results indicate one significant $\mathrm{F}$ test for the quadratic change component for 5HTT where risk allele carriers were less variable than noncarriers (see Figure 1). Thus, the results for Thurstone suggested one common candidate with Information, 5HTT. Unlike that for Information, $5 H T T$ risk carriers showed lower intrapair variability in the quadratic component for Thurstone indicating less sensitivity to the environment than nonrisk carriers. ESR1 showed a similar pattern in variance for quadratic estimates to that found for Information of lessened variability for carriers than noncarriers but was not significant $(p=.10)$.

\section{Working Memory}

The linear component for Digit Span exhibited no significant variance ratio tests. Only the $B C H E$ candidate 
Table 3

Variance Ratio Test of Genotype-Environment Interaction for the Thurstone Picture Memory Task

\begin{tabular}{|c|c|c|c|c|c|c|c|c|c|c|c|c|}
\hline \multirow[b]{3}{*}{ Gene } & \multicolumn{6}{|c|}{ Linear change at 65 years } & \multicolumn{6}{|c|}{ Quadratic } \\
\hline & \multicolumn{2}{|c|}{ MSE } & \multicolumn{10}{|c|}{ MSE } \\
\hline & $\begin{array}{c}\text { No risk } \\
\text { allele }\end{array}$ & $\begin{array}{l}\text { Risk } \\
\text { allele }\end{array}$ & $N-$ & $N_{+}$ & $\begin{array}{c}\text { Risk: } \\
\text { not risk }\end{array}$ & $F$ & $\begin{array}{c}\text { No risk } \\
\text { allele }\end{array}$ & $\begin{array}{l}\text { Risk } \\
\text { allele }\end{array}$ & $N-$ & $N_{+}$ & $\begin{array}{c}\text { Risk: } \\
\text { not risk }\end{array}$ & $F$ \\
\hline APOE(E4) & 0.03 & 0.02 & 65 & 26 & 0.72 & 1.40 & 1.9E-04 & $1.6 \mathrm{E}-04$ & 46 & 20 & 0.82 & 1.22 \\
\hline $\operatorname{ACE}(I)$ & 0.04 & 0.03 & 20 & 70 & 0.84 & 1.19 & $3.8 \mathrm{E}-04$ & $3.2 \mathrm{E}-04$ & 11 & 55 & 0.84 & 1.19 \\
\hline A2M(DEL) & 0.04 & 0.02 & 65 & 26 & 0.66 & 1.53 & $3.1 \mathrm{E}-04$ & 3.7E-04 & 45 & 21 & 1.20 & 1.20 \\
\hline $\operatorname{AGER}(T)$ & 0.03 & 0.03 & 66 & 25 & 0.88 & 1.14 & 3.0E-04 & 4.2E-04 & 47 & 19 & 1.42 & 1.42 \\
\hline $\mathrm{BCHE}(\mathrm{A})$ & 0.03 & 0.03 & 63 & 28 & 0.90 & 1.11 & $3.0 \mathrm{E}-04$ & $3.8 \mathrm{E}-04$ & 41 & 25 & 1.23 & 1.23 \\
\hline CATD(T) & 0.03 & 0.01 & 83 & 7 & 0.22 & $4.55^{*}$ & $3.4 \mathrm{E}-04$ & 2.2E-04 & 60 & 5 & 0.64 & 1.56 \\
\hline $\operatorname{DLST}(A)$ & 0.04 & 0.03 & 25 & 66 & 0.70 & 1.43 & $3.0 \mathrm{E}-04$ & $3.4 \mathrm{E}-04$ & 15 & 51 & 1.13 & 1.13 \\
\hline ESR1(G) & 0.03 & 0.03 & 64 & 26 & 0.99 & 1.01 & 2.1E-04 & $1.0 \mathrm{E}-04$ & 49 & 17 & 0.49 & 2.06 \\
\hline 5HTR2(A) & 0.03 & 0.04 & 47 & 43 & 1.30 & 1.30 & 2.7E-04 & 3.9E-04 & 29 & 36 & 1.41 & 1.41 \\
\hline $\mathrm{HTT}(\mathrm{G})$ & 0.03 & 0.04 & 68 & 23 & 1.48 & 1.48 & $2.2 \mathrm{E}-04$ & 6.9E-05 & 51 & 15 & 0.32 & $3.13^{*}$ \\
\hline $\operatorname{IDE}(C)$ & 0.02 & 0.05 & 59 & 32 & 2.21 & $2.21^{* *}$ & 2.7E-04 & 4.4E-04 & 42 & 24 & 1.65 & 1.65 \\
\hline $\mathrm{ILA}(\mathrm{T})$ & 0.04 & 0.02 & 55 & 36 & 0.68 & 1.48 & 3.7E-04 & $2.8 \mathrm{E}-04$ & 38 & 28 & 0.77 & 1.30 \\
\hline LRP(CC) & 0.03 & 0.03 & 17 & 73 & 1.18 & 1.18 & 4.3E-04 & $3.0 \mathrm{E}-04$ & 14 & 51 & 0.69 & 1.44 \\
\hline NoS3(T) & 0.03 & 0.03 & 47 & 44 & 0.91 & 1.10 & $2.4 \mathrm{E}-04$ & 4.1E-04 & 30 & 36 & 1.75 & 1.75 \\
\hline $\operatorname{TNF}(G)$ & 0.02 & 0.04 & 30 & 61 & 1.75 & $1.75^{t}$ & 1.1E-04 & 2.2E-04 & 22 & 44 & 1.94 & $1.94^{\mathrm{t}}$ \\
\hline
\end{tabular}

Note: ${ }^{*} p<.05 ;{ }^{* *} p<.01 ;{ }^{t}=p<.10$.

Risk allele (or genotype) in parentheses next to gene symbol. $M S E=$ Mean squares error as a measure of within-pair variability. $N-=$ the number of MZ pairs who do not carry the putative risk allele or do not have the risk genotype (i.e., LRP). $N_{+}=$the number of MZ pairs who do carry the putative risk allele or have the risk genotype (i.e., LRP).

suggested trend significance. Thus, no further analyses were conducted for Digit Span.

\section{Social and Stress Factors}

Variance ratio tests indicated genotype-environment interaction for memory-related cognitive change. However, while the gene candidates were specified, the environmental factors were anonymous. Thus, our last step was to consider the possibility that social or stressful environmental components may be associated with the observed genotype-environment interactions described above. In particular it was striking that certain candidates may be implicated within-trait and across-trait growth parameters, that is, ESR1 and 5HTT. Rather than compute all possible tests of association with social and stress factors we first

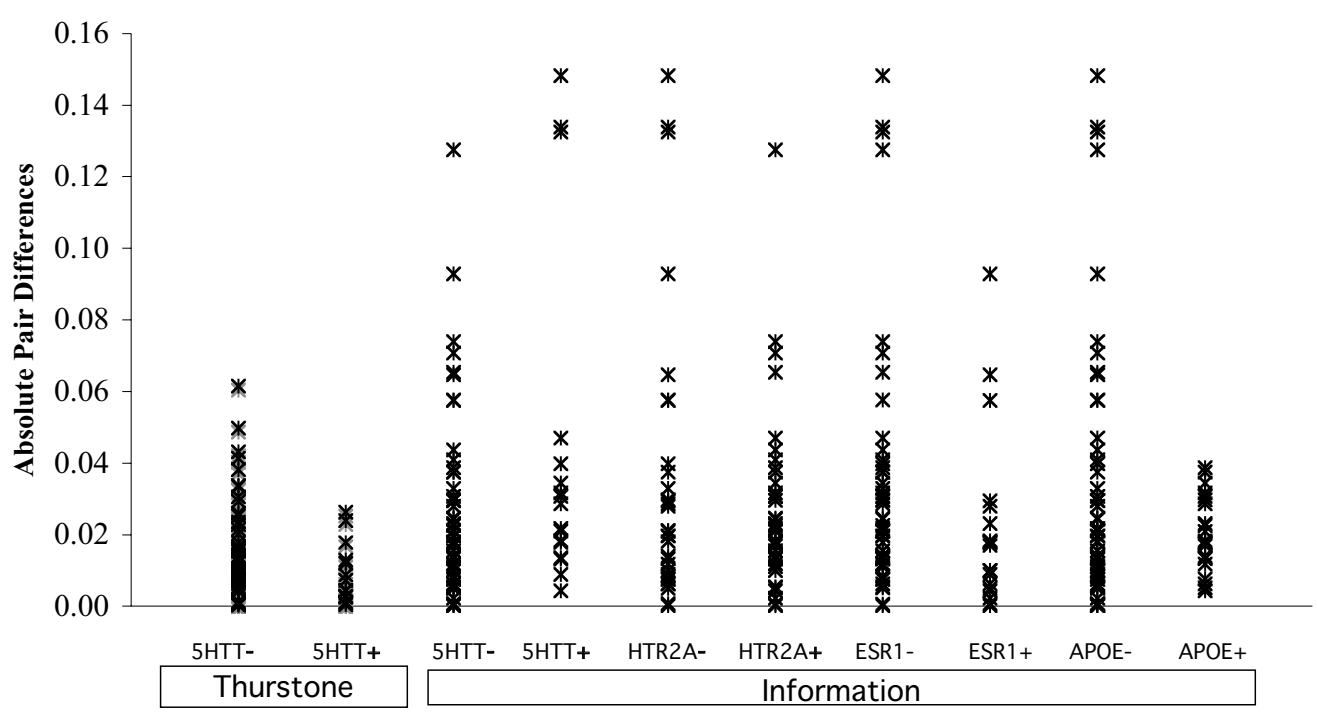

Figure 1

Absolute pair differences in untransformed quadratic parameters by genotype status. 
Table 4

Correlations Between MZ Pair Differences in Cognitive Change With Pair Differences in Social and Stress Factors

\begin{tabular}{|c|c|c|c|c|c|c|}
\hline & \multicolumn{6}{|c|}{ Social and stress factors } \\
\hline & Cognitive trait & Social support & Perceived support & Life events & Uncontrollable life events & CES-D \\
\hline \multicolumn{7}{|l|}{ Information } \\
\hline \multirow[t]{2}{*}{ Linear } & $r$ & .08 & .10 & .05 & -.02 & .12 \\
\hline & $N$ & 88 & 83 & 63 & 70 & 98 \\
\hline \multirow[t]{2}{*}{ Quadratic } & $r$ & .02 & .06 & .06 & -.11 & $.25^{*}$ \\
\hline & $N$ & 58 & 55 & 43 & 47 & 64 \\
\hline \multicolumn{7}{|c|}{ Thurstone Picture Memory } \\
\hline \multirow[t]{2}{*}{ Linear } & $r$ & -.06 & .09 & $.22^{\mathrm{t}}$ & .02 & -.05 \\
\hline & $N$ & 81 & 77 & 61 & 68 & 94 \\
\hline \multirow[t]{2}{*}{ Quadratic } & $r$ & .11 & -.04 & .26 & .06 & -.06 \\
\hline & $N$ & 53 & 51 & 42 & 45 & 60 \\
\hline
\end{tabular}

Note: ${ }^{*} p<.05 ;{ }^{* *} p<.01 ;{ }^{\mathrm{t}} p<.10$

Pair difference variables were transformed to reduce nonnormality (see text). $r=$ Pearson correlation coefficient; $N=$ number of $M Z$ pairs.

conducted a screen of possible correlation of absolute pair differences in social and stress factors with absolute pair differences in linear and quadratic EB growth parameter estimates for the Information subtest and Thurstone Picture Memory Task. Nonzero correlations might suggest that nonshared environmental influences are in common between social and stress factors and nonshared environmental influences observed for cognitive change. As described above it was necessary to transform the pair difference variables to reduce nonnormality. Table 4 presents Pearson correlation coefficients for the transformed pair difference variables. The correlations reflect the extent to which pair differences in social factors are associated with pair differences in cognitive change. The number of pairs varies widely for each social factor considered given that both members of the pair must have sufficient cognitive data as well. We considered correlations above .20 for further regression analysis. Pair differences in the quadratic parameter for Information were associated with pair differences in CES-D scores at $.25, p<.05$. For pair differences in linear and quadratic components of Thurstone Picture Memory, the correlations with pair differences in lifeevents were above .20 , although significance tests suggested $p$ values that exceeded .05 in both cases. Correlations remained essentially the same when pairs where one or both were demented were excluded.

Regression analyses were conducted next to examine whether gene candidates and stress factors identified in $\mathrm{G} \times \mathrm{E}$ and correlation analyses, respectively, might predict intrapair differences in cognitive change, that is, linear (Thurstone) and quadratic components (Information and Thurstone; see Table $5)$. Of particular interest is to consider whether genotype might interact with pair differences in the measured stress factors in their relationship with pair dissimilarity in cognitive change. If so, this would suggest the presence of differential genotypic sensitiv- ity to particular nonshared environmental factors. That is, we hoped to identify the nonshared ' $E$ ' in the $\mathrm{G} \times \mathrm{E}$ analyses conducted. The gene candidate predictors $(G)$ were coded such that those carrying the risk allele were coded 1 and noncarriers were coded as 0 . The transformed absolute intrapair differences in stress factors identified in the correlation analyses (total life events and CES-D) were considered the nonshared environmental factor (E) in the analyses. Finally, we constructed an interaction by multiplying the two predictors $(G \times E)$. Thus, a significant main effect of genotype $(G)$ would indicate the effect for risk allele carriers on absolute intrapair difference in the cognitive change parameter, that is, whether genotype is associated with differential environmental variability for carriers versus noncarriers. A significant $\mathrm{E}$ effect would suggest that environmental variability for stress or social factors was associated with environmental variability for cognitive change. A significant interaction $(G \times E)$ would indicate a differential effect of genotype on the relationship of environmental variability for the social or stress factor (E) with the environmental variability in the cognitive change parameter.

Two of eight regression analyses suggested a significant interaction of genotype by pair differences in stress. Both the APOE e 4 and ESR 1 candidates showed an interaction with pair differences in CES-D on absolute intrapair difference in the quadratic component for Information (see Table 5). As indicated by the regression analysis results, greater pair differences in CES-D scores are associated with greater pair differences in nonlinear change in Information performance over age for noncarriers of the APOE e4 and ESR 1 risk alleles (see Figures 1 and 2). The results suggest greater sensitivity to environmental factors associated with depressive symptoms for those who do not carry risk alleles (i.e., APOE e4 or ESR1 g allele, respectively). Results were essentially 
Table 5

Differences in Quadratic Change Predicted by Genotype and Variability in CES-D Depression Symptom or Life Event Scores

\begin{tabular}{|c|c|c|c|c|c|c|c|c|c|}
\hline Outcome & Genotype(G) & $\Delta$ Social factor (E) & $F$ & $d f$ & Int & G & $\mathrm{E}$ & $\mathrm{G} \times \mathrm{E}$ & $R^{2}$ \\
\hline \multicolumn{10}{|l|}{ Information } \\
\hline \multirow[t]{4}{*}{ Quadratic } & APOE (e4) & CES-D & $5.56^{* *}$ & $(3,59)$ & $-1.27^{* *}$ & $1.40^{* *}$ & $1.56^{* *}$ & $-2.06^{* *}$ & .22 \\
\hline & ESR1 $(g)$ & CES-D & $5.33^{* *}$ & $(3,59)$ & $-0.96^{* *}$ & 0.58 & $1.36^{* *}$ & $-1.51^{*}$ & .21 \\
\hline & $5 \mathrm{HTT}(\mathrm{g})$ & CES-D & 2.38 & $(3,59)$ & $-0.77^{*}$ & 0.65 & 0.85 & $-0.62^{*}$ & .11 \\
\hline & 5HTR2 (a) & CES-D & 1.59 & $(3,59)$ & -0.56 & -0.17 & 0.67 & 0.17 & .09 \\
\hline \multicolumn{10}{|c|}{ Thurstone Picture Memory } \\
\hline \multirow[t]{2}{*}{ Linear } & CATD $(t)$ & Life events & 0.98 & $(3,44)$ & -0.29 & 0.91 & 0.77 & -1.49 & .06 \\
\hline & IDE (c) & Life events & 1.01 & $(3,44)$ & -0.21 & -.13 & 0.75 & -.05 & .06 \\
\hline Quadratic & $5 \mathrm{HTT}(\mathrm{g})$ & Life events & 1.12 & $(3,37)$ & -0.42 & -0.50 & 0.62 & -0.05 & .08 \\
\hline
\end{tabular}

Pair difference variables were transformed to reduce nonnormality (see text). Int = intercept; $G$ = genotype; $E=$ pair differences in social variable; $\mathrm{G} \times \mathrm{E}=$ interaction of genotype by pair differences in social factor.

identical when pairs where one or both were demented were excluded.

\section{$\overline{\text { Discussion }}$}

The current study suggests the presence of gene-environment interaction for memory-related cognitive change, particularly for tasks requiring semantic or episodic memory. Possible candidate variability genes were identified as well as measured environmental factors that may moderate genetic effects on cognitive change. The candidate variability genes imply the involvement of serotonin, estrogen, and cholesterol pathways while the measured social and stress environmental factor indicate a possible role for depression-relevant environmental features that may moderate associations between genes and cognitive change on semantic memory.

Variance ratio tests suggested genotype-environment interactions for age-related change in memory-loaded cognitive tasks. Multiple 'variability genes' were identified for cognitive change, in particular, the ESR 1 and HTT candidates. Furthermore, nonshared environmental influences attributable to depressive symptoms may reflect in part the nonshared environmental influences for semantic memory change that interact with genotype, but only for those who do not carry the $A P O E$ e4 allele or noncarriers of the ESR1 risk allele. Thus, noncarriers of these two candidates may be more sensitive to depression-inducing or depression-reducing elements of the environment than those who carry the risk allele and thus show greater variation in semantic memory change. Put the other way, those who carry the risk allele may be relatively less affected by alterations in the environment.

The identification of APOE and ESR1 as variability genes for accelerating change in the semantic memory task (Information) is of interest given the well-known association of APOE and possibly ESR1 with cognitive change and $\mathrm{AD}$ risk as well as evidence suggesting that the association between ESR1 variants with $\mathrm{AD}$ risk may be mediated by apoE expression (Corbo et al., 2006). APOE has been associated with compromised semantic memory performance in nondemented adults where e4 carriers demonstrated poorer performance on word fluency tasks than noncarriers (Rosen et al., 2005). However, differential preclinical memory profiles have not been routinely noted for $A P O E$ e4 carriers versus noncarriers (Estevez-Gonzalez et al., 2004).

The identification of serotonin-related candidates $5 H T T$ and HTR2A as variability genes implicates the serotonin system in variability in memory-related cognitive change. We note a prior association with $5 H T R 2 A$ and degree of episodic figural memory change (Thurstone) over age (Reynolds, Jansson, et al., 2006). In the current study HTR2A was only associated as variability gene for quadratic change for semantic memory (Information). Given that serotonin candidates have been associated primarily with differential risk of depressive disorders, we find it surprising that there was a lack of interaction between intrapair differences in CES-D and 5HTT or 5HTR2A affecting environmental variability for semantic memory or episodic figural memory change.

Intrapair variability for depressive symptoms were positively associated with intrapair differences in semantic memory change but only for those who do not carry an $A P O E$ e4 allele (i.e., $A P O E$ e2e2, e2e3, or e $3 \mathrm{e} 3$ genotypes), or those who do not carry the ESR 1 risk allele. Altogether, those who do not carry the risk allele for APOE or ESR1, respectively, may be more sensitive to depression-inducing or depressionreducing elements of the environment. This might suggest that interventions for maintaining cognitive resiliency, including reducing stressors that otherwise could lead to increases in depressive symptoms, would have greater impact for those who do not carry risk alleles. This may paint a rather deterministic picture for $A P O E$ e 4 carriers at first glance. Yet, evidence sug- 
Into $\mathrm{O}$ rank-norm

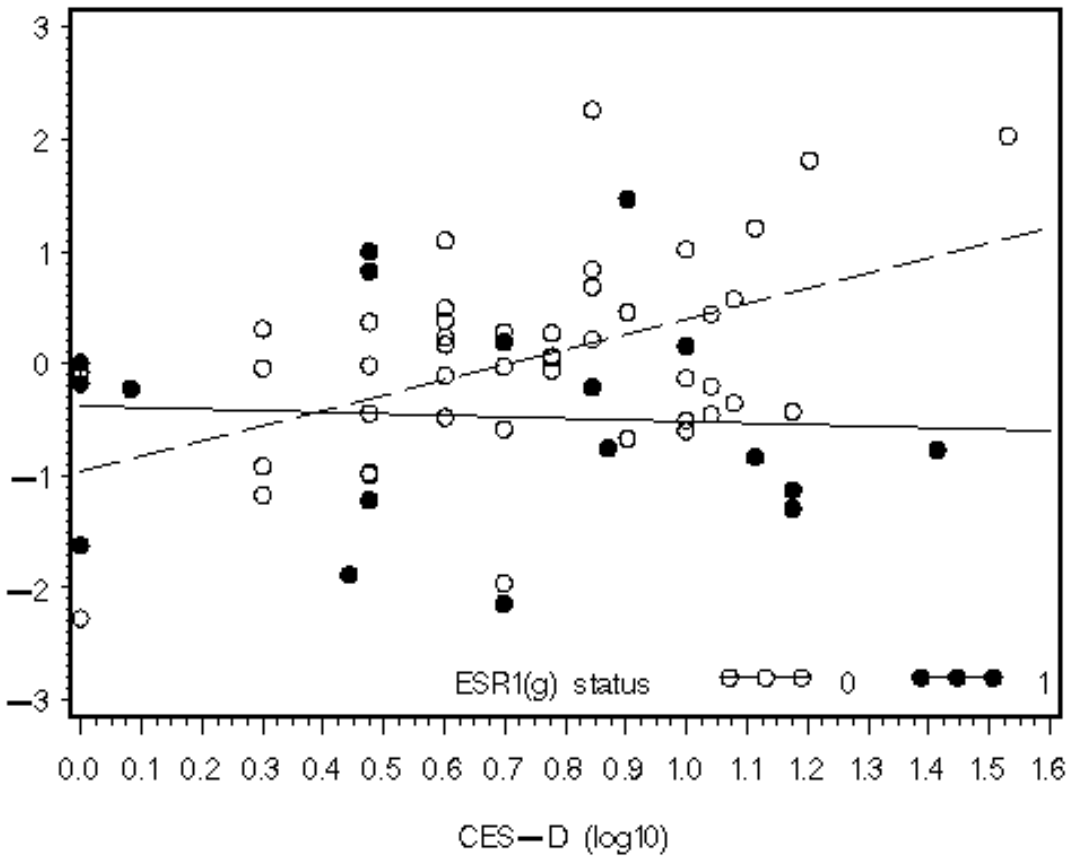

Info 9 rank-nom

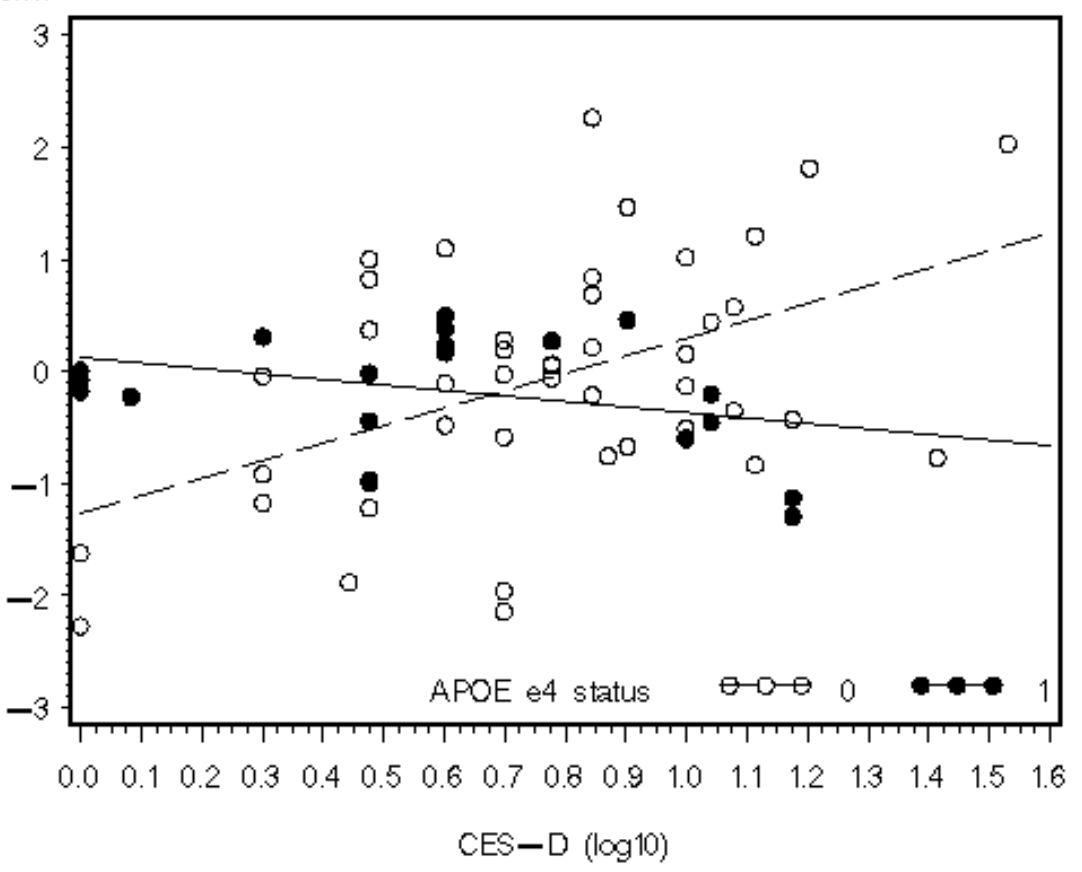

Figure 2

Absolute pair differences in quadratic change in Information subtest and CES-D (transformed): (a) APOE genotype status; (b) ESR1 genotype status.

gests that individuals carrying even two copies of the e4 alleles do not inevitably get AD even in late old age (see Rogaeva et al., 2006). Furthermore, multiple clinical studies of adults suggest that APOE e4 carriers may respond better to interventions that moderate dietary fat (e.g., via better lipid profiles) than noncarriers (see Corella \& Ordova, 2005), although standardized replication studies are needed in light of the many negative studies reported. Put more properly into perspective, our results suggest that there may be a narrower range of environmental factors that one could target for intervention for APOE and ESR1 risk allele carriers.

In prior analyses of candidate gene association with mean differences in cognitive change in nondemented SATSA twins, APOE was associated with change in the working memory measure Digit Span (Reynolds, Prince, et al., 2006), but was not likewise 
identified as a variability gene for working memory in the present study. However, in the former study the amplified decline was observed for e4 homozygotes, whereas in the present study we considered e4 heteroand homzygotes together for sample size considerations. Similarly, A2M and 5HTR2A were associated with mean differences in episodic figural recognition change over age (Thurstone Picture Memory) in prior studies (Reynolds, Jansson, et al., 2006; Reynolds, Prince, et al., 2006) but in the present case neither were identified as 'variability genes' for episodic figural recognition change.

Thus far we have focused the discussion on wellknown gene candidates or those showing multiple associations with growth parameters within and in one case across cognitive tests. Other variability genes may include CATD and IDE. The current findings suggest CATD is predictive of differential environmental variability in semantic memory performance at 65 years (Information) and both CATD and IDE as predictive of differential environmental variability for linear change at 65 years, that is, turning points, for episodic figural memory performance (Thurstone). However, there is little to suggest what the environmental contexts might be amongst the social and stress factors considered.

Overall, sample sizes may limit the ability to find associations for the growth parameter indices of change because multiple time points are required to estimate them. Low power of the variance ratio test to find $\mathrm{G} \times \mathrm{E}$ effects could have hampered efforts further (see Martin et al., 1983). Where multiple associations were found they were found primarily within rather than across traits, that is, the Information subtest, which may be explained in part by correlation among the growth parameters. The variation in the growth parameters estimated reflects systematic growth variance given the fitted quadratic model; that is, occasion-specific error is removed, which may have aided the current study in finding the reported associations although sample size was constrained. Additional studies ought to be considered to see if the identified gene candidates are replicated.

\section{Limitations}

Limitations of the current study include the use of a two-stage procedure to analyze $\mathrm{G} \times \mathrm{E}$ effects on cognitive change. We estimated EB indices of growth parameters prior to conducting separate heterogeneity or variance ratio tests on multiple correlated growth parameter facets. Type I error rate may be a concern because of the multiple tests conducted ( 15 candidates per growth parameter considered). We screened first for evidence of heterogeneity and then proceeded to variance ratio tests which reduced the number of tests required. We then observed eight significant findings out of 45 tests for Information across intercept, linear slope and quadratic, three of 30 tests for Thurstone across linear slope and quadratic, and none out of 15 tests for Digit Span for the linear slope. If we applied a Bonferroni adjustment within cognitive trait assuming moderate correlation amongst growth parameters, only the 5HTT and APOE candidates would remain significant for the linear and quadratic terms for the Information subtest as identified. We also reduced the number of regression analyses with putative social/stress factors by examining the presence of association between intrapair differences in social-stress factors with intrapair differences in cognitive change before proceeding to analyses including genotype. In so doing we may have missed possible antagonistic interaction effects.

Two of the cognitive tests considered are not 'pure' measures of memory per se, that is, Information and Digit Span. Information taps semantic memory but is more commonly considered a marker of crystallized intelligence. We used the sum of forward and backward Digit Span. Digit Span forward may more prominently tap attention, although working memory is captured by backward Digit Span. Altogether we may be measuring memory-relevant general cognition rather than select memory process.

Scaling factors and true $\mathrm{G} \times \mathrm{E}$ may both lead to evidence of heterogeneity (Martin, 2000), a precursor to testing for variance differences by genotypes in the present study. Rescaling the growth parameters using a rank-normalization procedure did not result in the disappearance of all significant heterogeneity, particularly for the linear and quadratic parameters. Nonetheless, we cannot exclude the possibility that the present results may in part reflect scaling artifacts rather than true $\mathrm{G} \times \mathrm{E}$. Replication studies using other twin samples and other cognitive measures are needed.

The $\mathrm{G} \times \mathrm{E}$ analyses necessarily included complete $\mathrm{MZ}$ twin pairs such that both members had to have data from at least one cognitive testing occasion to be considered for tests of intercept, two or more occasions for tests of linear slope, and three or more occasions for tests of the quadratic parameter. If $G \times$ $E$ interaction effects were present for age at death or dropout this could have biased the current results. For example, if $A P O E$ e4 allele status was associated with attrition then the remaining e4 positive pairs may be less variable on verbal change due to their joint survival.

\section{Conclusions}

The current study highlights the importance of genecontext interplay on longitudinal cognitive resilience and decline in humans. Ours is the first to suggest 'variability genes' for cognitive aging phenotypes. Variability genes include the well-known candidate APOE as well as ESR1, 5HTR2A, 5HTT, CATD and $I D E$. Most associations were found for variability in change in a task tapping semantic memory although one common candidate related to variability in change in episodic memory (5HTT). Nonshared environmental influences associated with depressive symptoms 
may moderate the $\mathrm{G} \times \mathrm{E}$ relationship observed for ESR 1 and APOE and variation in change for semantic memory. Noncarriers of putative risk alleles may be relatively more sensitive to environmental change; thus, the contexts that facilitate or reduce depressive symptoms may also lead to semantic memory decline or resiliency, suggesting a target for interventions. However, replications of the identified variability genes and further work on other social and contextual factors are warranted.

\section{Author Note}

Analytical work and genotyping was supported by R01-AG17561. The Swedish Adoption/Twin Study of Aging (SATSA) is supported by R01-AG04563 and AG10175, The MacArthur Foundation Research Network on Successful Aging, and the Swedish Council for Social Research (97:0147:1B). We acknowledge and thank Jonathan A. Prince, Anthony Brookes, Lars Feuk, and Mårten Jansson for their work on genotyping of the candidates described in this manuscript.

\section{Acknowledgments}

The authors acknowledge funding support from the National Institute on Aging. The views expressed are those of the authors of this paper, and not the National Institute on Aging, the National Institutes of Health or the Department of Health and Human Services.

\section{References}

Anstey, K., \& Christensen, H. (2000). Education, activity, health, blood pressure and apolipoprotein $\mathrm{E}$ as predictors of cognitive change in old age: a review. Gerontology, 46, 163-177.

Ariza, M., Pueyo, R., Matarin Mdel, M., Junque, C., Mataro, M., Clemente, I., Moral, P., Poca, M. A., Garnacho, A., \& Sahuquillo J. (2006). Influence of APOE polymorphism on cognitive and behavioural outcome in moderate and severe traumatic brain injury. Journal of Neurology, Neurosurgery and Psychiatry, 77, 1191-1193.

Beland, F., Zunzunegui, M. V., Alvarado, B., Otero, A., \& Del Ser, T. (2005). Trajectories of cognitive decline and social relations. Journals of Gerontology. Series B: Psychological Sciences and Social Sciences, 60, P320-P330.

Berg, K., Kondo, I., Drayna, D., \& Lawn, R. (1989). 'Variability gene' effect of cholesteryl ester transfer protein (CETP) genes. Clinical Genetics, 35, 437-445.

Bergeman, C. S., Plomin, R., Pedersen, N. L., McClearn, G. E., \& Nesselroade, J. R. (1990). Genetic and environmental influences on social support: the Swedish Adoption/Twin Study of Aging. Journal of Gerontology, 45, P101-106.

Blomqvist, M. E., Reynolds, C., Katzov, H., Feuk, L., Andreasen, N., Bogdanovic, N., Blennow, K.,
Brookes, A. J., \& Prince, J. A. (2006). Towards compendia of negative genetic association studies: An example for Alzheimer disease. Human Genetics, 119, 29-37.

Borenstein, A. R., Copenhaver, C. I., \& Mortimer, J. A. (2006). Early-life risk factors for Alzheimer disease. Alzheimer Disease and Associated Disorders, 20, 63-72.

Brunson, K. L., Kramár, E., Lin, B., Chen, Y., Colgin, L. L., Yanagihara, T. K., Lynch, G., \& Baram, T. Z. (2005). Mechanisms of late-onset cognitive decline after early-life stress. Journal of Neuroscience, 25, 9328-9338.

Corbo, R. M., Gambina, G., Ruggeri, M., \& Scacchi, R. (2006). Association of estrogen receptor alpha (ESR1) PvuII and XbaI polymorphisms with sporadic Alzheimer. Dementia and Geriatric Cognitive Disorders, 22, 67-72.

Corella, D., \& Ordovas, J. M. (2005). Single nucleotide polymorphisms that influence lipid metabolism: Interaction with dietary factors. Annual Review of Nutrition, 25, 341-390.

de Knijff, P., Boomsma, D. I., de Wit, E., Kempen, H. J., Gevers Leuven, J. A., Frants, R. R., \& Havekes, L. M. (1993). The effect of the apolipoprotein E phenotype on plasma lipids is not influenced by environmental variability: results of a Dutch twin study. Human Genetics, 91, 268-272.

Duman, R. S. (2005). Neurotrophic factors and regulation of mood: Role of exercise, diet and metabolism. Neurobiology of Aging, 26, 88-93.

Estevez-Gonzalez, A., Garcia-Sanchez, C., Boltes, A., Otermin P., Baiget M., Escartin A., del Rio E., Gironell A., \& Kulisevsky J. (2004). Preclinical memory profile in Alzheimer patients with and without allele APOE-epsilon4. European Neurology, 51, 199-205.

Falconer, D. S. (1989). Introduction to quantitative genetics (3rd ed.). New York: John Wiley \& Sons.

Finkel, D., \& Pedersen, N. L. (2004). Processing speed and longitudinal trajectories of change for cognitive abilities: The Swedish Adoption/Twin Study of Aging. Aging, Neuropsychology, and Cognition. Special Issue: Longitudinal studies of cognitive aging, 11, 325-345.

Finkel, D., Reynolds, C. A., McArdle, J. J., Gatz, M., \& Pedersen, N. L. (2003). Latent growth curve analyses of accelerating decline in cognitive abilities in late adulthood. Developmental Psychology, 39, 535-550.

Fisher, R. A. (1925). The resemblance between twins, a statistical examination of Lauterbach's measurements. Genetics, 10, 569-579.

Gatz, M., Prescott, C. A., \& Pedersen, N. L. (2006). Lifestyle risk and delaying factors. Alzheimer Disease and Associated Disorders, 20, S84-S88. 
Harden, K. P., Turkheimer, E., \& Loehlin, J. C. (2007). Genotype by environment interaction in adolescents' cognitive aptitude. Behavior Genetics, 37, 273-283..

Henderson, S., Duncan-Jones, P., Byrne, D. G., \& Scott, R. (1980). Measuring social relationships: The Interview Schedule for Social Interaction. Psychological Medicine, 10, 723-734.

Hibberd, C., Yau, J. L., \& Seckl, J. R. (2000). Glucocorticoids and the ageing hippocampus. Journal of Anatomy, 197, 553-562.

Holmes, T. H., \& Rahe, R. H. (1967). The Social Readjustment Rating Scale. Journal of Psychosomatic Research, 11, 213-218.

Holtzman, R. E., Rebok, G. W., Saczynski, J. S., Kouzis, A.C., Wilcox Doyle, K., \& Eaton, W.W. (2004). Social network characteristics and cognition in middle-aged and older adults. The Journals of Gerontology. Series B: Psychological Sciences and Social Sciences, 59, P278-284.

Jansson, M., Gatz, M., Berg, S., Johansson, B., Malmberg, B., McClearn, G. E., Schalling, M., \& Pedersen, N. L. (2003). Association between depressed mood in the elderly and a 5-HTR2A gene variant. American Journal of Medical Genetics. Part B, Neuropsychiatric Genetics, 120, 79-84.

Jonsson, C. -O., \& Molander, L. (1964). Manual till CVB-skalan [Manual of the CVB Scales]. Stockholm: Psykologi Förlaget.

Kang, J. H., Logroscino, G., De Vivo, I., Hunter, D., \& Grodstein, F. (2005). Apolipoprotein E, cardiovascular disease and cognitive function in aging women. Neurobiology of Aging, 26, 475-484.

Kravitz, H. M., Meyer, P. M., Seeman, T. E., Greendale, G. A., \& Sowers, M. R. (2006). Cognitive functioning and sex steroid hormone gene polymorphisms in women at midlife. American Journal of Medicine, 119(9 Suppl. 1), S94-S102.

Lichtenstein, P., De Faire, U., Floderus, B., Svartengren, M., Svedberg, P., \& Pedersen, N. L. (2002). The Swedish Twin Registry: A unique resource for clinical, epidemiological and genetic studies. Journal of Internal Medicine, 252, 184-205.

Magnus, P., Berg, K., Borreson, A. -I., \& Nance, W. E. (1981). Apparent influence of marker genotypes on variation in serum cholesterol in monozygotic twins. Clinical Genetics, 35, 437-445.

Magri, F., Cravello, L., Barili, L., Sarra, S., Cinchetti, W., Salmoiraghi, F., Micale, G., \& Ferrari, E. (2006). Stress and dementia: The role of the hypothalamicpituitary-adrenal axis. Aging Clinical and Experimental Research, 18, 167-170.

Martin, N. G. (2000). Gene-environment interaction and twin studies. In T. D. Spector, H. Snieder, \& A. J. MacGregor (Eds.), Advances in twin and sib-pair analysis (pp. 144-150). London: Greenwich Medical Media.
Martin, N. G., Rowell, D. M., \& Whitfield, J. B. (1983). Do the $\mathrm{MN}$ and Jk systems influence environmental variability in serum lipid levels? Clinical Genetics, 24, $1-14$.

Mayeux, R., Ottman, R., Maestre, G., Ngai, C., Tang, M. X., Ginsberg, H., Chun, M., Tycko, B., \& Shelanski, M. (1995). Synergistic effects of traumatic head injury and apolipoprotein-epsilon 4 in patients with Alzheimer's disease. Neurology, 45, 555-557.

Moceri, V. M., Kukull, W. A., Emanual, I., van Belle, G., Starr, J. R., Schellenberg, G. D., McCormick, W. C., Bowen, J. D., Teri, L., \& Larson, E. B. (2001). Using census data and birth certificates to reconstruct the early-life socioeconomic environment and the relation to the development of Alzheimer's disease. Epidemiology, 12, 383-389.

Moceri, V. M., Kukull, W. A., Emanuel, I., van Belle, G., \& Larson, E. B. (2000). Early-life risk factors and the development of Alzheimer's disease. Neurology, 54, 415-420.

Pedersen, N. L., McClearn, G. E., Plomin, R., Nesselroade, J. R., Berg, S., \& DeFaire, U. (1991). The Swedish Adoption/Twin Study of Aging: An update. Acta Geneticae Medicae et Gemellologiae, 40, 7-20.

Persson, G. (1980). Life event ratings in relation to sex and marital status in a 70 -year-old urban population. Acta Psychiatrica Scandinavica, 62, 112-118.

Plomin, R., Lichtenstein, P, Pedersen, N. L., McClearn, G. E., \& Nesselroade, J. R. (1990). Genetic influence on life events during the last half of the life span. Psychology and Aging, 5, 25-30.

Porrello, E., Monti, M. C., Sinforiani, E., Cairati, M., Guaita, A., Montomoli, C., Govoni, S., \& Racchi, M. (2006). Estrogen receptor alpha and APOEepsilon4 polymorphisms interact to increase risk for sporadic $\mathrm{AD}$ in Italian females. European Journal of Neurology, 13, 639-644.

Prince, J. A., \& Brookes, A. J. (2001). Towards highthroughput genotyping of SNPs by dynamic allele-specific hybridization. Expert Review of Molecular Diagnostics, 1, 352-358.

Prince, J. A., Feuk, L., Sawyer, S. L., Gottfries, J., Ricksten, A., Nagga, K., Bogdanovic, N., Blennow, K., \& Brookes A. J. (2001). Lack of replication of association findings in complex disease: An analysis of 15 polymorphisms in prior candidate genes for sporadic Alzheimer. European Journal of Human Genetics, 9, 437-444.

Radloff, L. S. (1977). The CES-D Scale: A self-report depression scale for research in the general population. Applied Psychological Measurement, 1, 385-401.

Reynolds, C. A., Finkel, D., McArdle, J. J., Gatz, M., Berg, S., \& Pedersen, N. L. (2005). Quantitative genetic analysis of latent growth curve models of cog- 
nitive abilities in adulthood. Developmental Psychology, 41, 3-16.

Reynolds, C. A., Jansson, M., Gatz, M., \& Pedersen, N. L. (2006). Longitudinal change in memory performance associated with HTR2A polymorphism. Neurobiology of Aging, 27, 150-154.

Reynolds, C. A., Prince, J. A., Feuk, L., Gatz, M., \& Pedersen, N. L. (2006). Longitudinal memory performance during normal aging: Twin association models of APOE and other Alzheimer candidate genes. Behavior Genetics, 36, 185-194

Rogaeva, E., Kawarai, T., \& George Hyslop, P. S. (2006). Genetic complexity of Alzheimer's disease: Successes and challenges. Journal of Alzheimer's Disease, 9, 381-387.

Rosen, V. M., Sunderland, T., Levy, J., Harwell, A., McGee, L., Hammond, C., Bhupali, D., Putnam, K., Bergeson, J., \& Lefkowitz, C. (2005). Apolipoprotein $\mathrm{E}$ and category fluency: Evidence for reduced semantic access in healthy normal controls at risk for developing Alzheimer. Neuropsychologia, 43, 647-658.
Sachs-Ericsson, N., Joiner, T., Plant, E. A., \& Blazer, D. G. (2005). The influence of depression on cognitive decline in community-dwelling elderly persons. American Journal of Geriatric Psychiatry, 13, 402-408.

Thurstone, L. L. (1938). Primary mental abilities. Chicago: University of Chicago Press.

VonDras, D. D., Powless, M. R., Olson, A. K., Wheeler, D., \& Snudden, A. L. (2005). Differential effects of everyday stress on the episodic memory test performances of young, mid-life, and older adults. Aging and Mental Health, 9, 60-70.

Wetherell, J. L., Gatz, M., Johansson, B., \& Pedersen, N. L. (1999). History of depression and other psychiatric illness as risk factors for Alzheimer disease in a twin sample. Alzheimer Disease and Associated Disorders, 13, 47-52.

Yaffe, K., Lui, L. Y., Grady, D., Stone, K., \& Morin, P. (2002). Estrogen receptor 1 polymorphisms and risk of cognitive impairment in older women. Biological Psychiatry, 51, 677-682.

\section{$\overline{\text { Appendix A }}$}

\section{Identity of Candidate Polymorphisms}

\begin{tabular}{|c|c|c|c|c|}
\hline \multirow[b]{2}{*}{ Gene Symbol } & \multicolumn{4}{|c|}{ Database identification } \\
\hline & HGVBASE & $\mathrm{dbSNP}$ & Accession no. & Alleles \\
\hline$A 2 M$ & IND000007566 & ss2419769 & & ACCAT/_ \\
\hline$A C E$ & SNP000006569 & rs4343 & & $A / G$ \\
\hline AGER & SNP000005174 & rs1800684 & & $A / T$ \\
\hline APOE(e4) & SNP000002328 & rs429358 & & $\mathrm{C} / \mathrm{T}$ \\
\hline$A P O E(\mathrm{e} 2)$ & SNP000002314 & rs7412 & & $\mathrm{C} / \mathrm{T}$ \\
\hline$B C H E$ & SNP000011184 & rs1803274 & & $A / G$ \\
\hline CATD & SNP000008899 & rs17571 & & $\mathrm{C} / \mathrm{T}$ \\
\hline$D L S T$ & SNP000002340 & rs1799900 & & $A / G$ \\
\hline ESR1a & SNP000002389 & rs1801132 & & $\mathrm{C} / \mathrm{G}$ \\
\hline 5HTR2A & - & - & S78723 [promotor -1438 G/A] & $A / G$ \\
\hline $5 H T T$ & - & - & U79746 [exon1B -925 T/G] & $T / G$ \\
\hline$I D E$ & SNP001280949 & rs2251101 & & $\mathrm{C} / \mathrm{T}$ \\
\hline$I L A$ & SNP000003482 & rs1800587 & & $\mathrm{C} / \mathrm{T}$ \\
\hline$L R P 1$ & SNP000002603 & rs1799986 & & $\mathrm{C} / \mathrm{T}$ \\
\hline NOS3 & SNP000002600 & rs1799983 & & $\mathrm{G} / \mathrm{T}$ \\
\hline TNFRFS6 & SNP000005172 & rs1800682 & & $\mathrm{G} / \mathrm{A}$ \\
\hline
\end{tabular}

